\title{
ENTREVISTA CON FRANCISCO MARTÍNEZ SÁNCHEZ (Diciembre, 2016)
}

\author{
Realizada por Mํㅗ Paz Prendes Espinosa, Directora de RIITE
}

\begin{abstract}
Francisco Martínez Sánchez comenzó su vida profesional como maestro y enseguida se incorporó a la Universidad de Murcia como profesor de Tecnología Educativa. En la Universidad de Murcia creó el "Grupo de Investigación en Tecnología Educativa" (GITE), fue Vicedecano de la Facultad de Ciencias de la Educación, Director del Servicio de Recursos Audiovisuales y Director del Departamento de Didáctica y Organización Escolar. Actualmente es Profesor Honorario de la Universidad de Murcia y Presidente de Edutec, Asociación profesional internacional para el Desarrollo de la Tecnología Educativa.
\end{abstract}

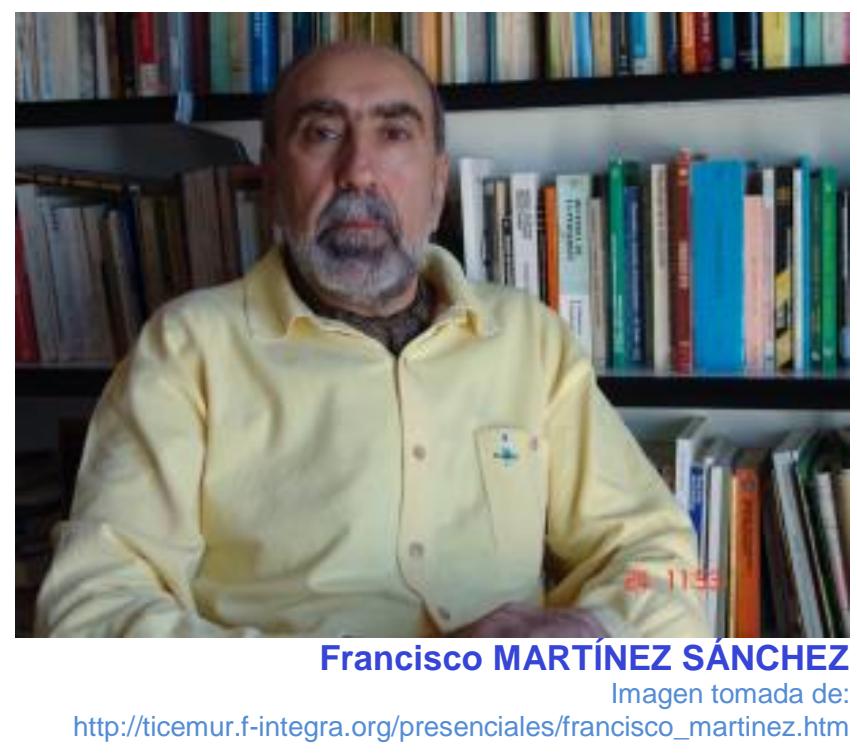

Es conocido por su amplia trayectoria en relación con la Tecnología Educativa, desde sus primeras investigaciones sobre la enseñanza asistida por ordenador y el LOGO hasta sus más recientes trabajos centrados en el análisis de los modelos de telenseñanza, el teletrabajo, la comunicación en red y en general los usos educativos de las tecnologías.

Es un honor y un orgullo hacerle esta entrevista, pues además de todo ello, ha sido y es mi maestro. Para mí y para todos los que le conocemos, es simplemente "Paco".

Tras una experiencia ya larga que ha estado vinculada desde siempre a la Tecnología Educativa, creemos que eres la persona que mejor conoce la evolución de la Tecnología Educativa en estos años. Desde los orígenes, allá por los tiempos de Skinner, hasta la actualidad, ¿qué destacarías en la evolución de la Tecnología Educativa como cuerpo de conocimiento, como ámbito de construcción de la ciencia?

Los comienzos en España fueron con los medios audiovisuales y lo único que interesaba era ver como se podían usar estos medios, diapositivas, retroproyector, cine, etc. en la enseñanza, lo cual pasaba por saber manejar esos aparatos pero sin prácticamente ningún sustento pedagógico. La Tecnología Educativa, y no solo Skinner, aportó ese sustento que faltaba, lo que supuso un salto cualitativo muy significativo permitiendo ir más allá que el mero instrumentalismo de la etapa anterior. Es esta época cuando la TE tiene una presencia académica clara y propia, diferenciada del resto de conocimientos necesarios en la formación y ejercicio docentes.

En el momento actual me da la impresión de que se ha regresado a la etapa primera en la que lo realmente significativo es el uso de los aparatos y se ha dejado a un lado todo el corpus de conocimientos que justifican y dan sentido a la incorporación de unos equipos concretos. Esta situación lleva a que la TE haya perdido su sentido y su personalidad. 
Situémonos en España. Se habla mucho del informe PISA, de los informes de la OCDE,... y nunca se habla bien en relación con nuestro sistema educativo. ¿Cuál es tu opinión? ¿Crees que estos datos reflejan la realidad de nuestra educación?

Creo que buena parte de los sistemas de evaluación que se utilizan para este tipo de informes están pensados a partir de un modelo de enseñanza, un contexto social y económico, lo que inevitablemente lleva a que aquellos que no se corresponde con ese modelo salgan mal parados.

No quiero con esto decir que nuestro sistema sea bueno, evidentemente es sensiblemente mejorable, pero si se quiere mejorar en las evaluaciones que nos vienen de fuera, habrá que cambiar el modelo y ajustarlo a lo que se evalúa. Pero si lo que se quiere es mejorarlo, habrá que empezar por la formación del profesorado, tanto la inicial como la continua, tomando como referente el modelo en su totalidad y ajustando esta formación a unos roles acordes con la situación y el conocimiento actual.

En la medida en que no se revise el modelo y con él la formación docente, difícilmente se podrá llegar a tener un sistema de enseñanza óptimo.

Y en relación con ello, ¿crees que las tecnologías pueden ser un elemento que contribuya a la mejora del sistema y a la mejora de estos datos?

La tecnología por sí sola no puede mejorar la enseñanza. La incorporación de tecnologías sin ningún tipo de justificación didáctica no puede solucionar nada, solo dar la impresión a la sociedad de que se está a la última, pero nada más. Uno de los referentes en mi formación como docente decía una y otra vez: Respondan a la pregunta ¿Por qué este medio aquí y ahora? En estos momentos la respuesta que más se oye es más propia de mensajes publicitarios que de reflexión pedagógica.

Dicho esto, hay que añadir que efectivamente las tecnologías disponibles en este momento pueden mejorar sensiblemente los procesos de enseñanza y con ellos el aprendizaje de los alumnos, pero ello pasa por responder adecuadamente a la pregunta anterior y por cambiar la formación del profesorado y con ella, posiblemente su función como docentes.

Con la irrupción de los medios digitales y muy especialmente con la llegada de Internet, hemos podido observar cómo han cambiado las escuelas... ¿o realmente no? ¿En tu opinión son las escuelas actuales distintas de las escuelas de hace 20 años?

Si hablamos en general, no hay mucho cambio (excepciones existen y muy significativas). Para poder corroborar lo que digo solo hace falta entrar a un aula y ver la distribución de las mesas. En muchos casos se ha cambiado la pizarra de tiza por la digital, incluso he sido testigo de centros en los que se ha cambiado el diseño de los pupitres para poder integrar en cada uno de ellos un ordenador, ordenador que sí estaba empotrado en el mobiliario pero no integrado en el aula desde una perspectiva educativa. Salvo esos cambios materiales, el resto sigue casi igual que hace años.

Realmente no he visto mucho cambio pedagógico. De otra naturaleza puede ser, pero esos cambios no tengo a la certeza de que sean para mejorar.

Se habla con frecuencia de los "nativos digitales", esa generación de aprendices que conocen bien las tecnologías porque han nacido con ellas. ¿Crees que estos aprendices son cognitivamente distintos de generaciones anteriores? ¿Crees que realmente se justifica el uso de este concepto?

No creo que la teoría de la evolución de Darwin constatase en ningún momento que los cambios evolutivos de los seres humanos mutasen a una velocidad tal que un individuo se transformase como consecuencia de haber nacido en un sitio determinado en un momento concreto. 
Evidentemente cuando desde bien pequeño se tiene acceso a unas determinadas cosas novedosas, se van adquiriendo destrezas para su manejo que los adultos pueden no tener -o que sea más complicado que las adquieran-. Esto no es algo exclusivo de los medios digitales. Sí ocurre que la adquisición de esas destrezas conlleva un tipo de razonamiento acorde con las peculiaridades del medio tecnológico de que se trate, pero de eso a decir que son cognitivamente diferentes por el hecho de haber nacido en un momento determinado es una falacia.

Los informes internacionales nos hablan de un futuro marcado por el e-learning, el aula invertida o el acceso abierto a la información y los recursos digitales. Desde la atalaya, ¿cómo se ve el futuro de la enseñanza? Y muy especialmente, sabiendo de su amplio conocimiento del sistema universitario, ¿cómo cree que será el futuro de las universidades?

Centrándome exclusivamente en la enseñanza universitaria, creo que ha de cambiar sensiblemente la totalidad de lo que hace en relación con la docencia. Se trata de alumnos adultos que saben lo que quieren aprender y para qué. Llegan con una formación que les debe permitir ser responsables últimos de su "aproximación al conocimiento", de organizar su tiempo y de evaluar las diferentes fuentes de información. Si en estos momentos no llegan así, es que los sistemas pre-universitarios no están acordes con las posibilidades actuales.

La universidad ha de ser en los años próximos más un lugar de evaluación de contenidos por parte de los alumnos y de tutoría por parte de los profesores. Los contenidos están disponibles en infinidad de fuentes de información, el problema está en saber diferenciar la que es significativa y la que no, y ahí radica la función de la Universidad: formar para valorar y ser capaces de ser críticos, pero con criterio.

Y llegamos al punto en que nos tomamos un café y hablamos de nuestras cosas. Gracias por el tiempo que nos has dedicado, porque ambos sabemos ya del valor del tiempo. Y gracias por enseñarnos siempre tanto. De forma similar a las medallas y premios que con la "gamificación" se han puesto de moda, podemos decir que RIITE tiene la suya propia por haber podido contar con el profesor Francisco Martínez Sánchez en nuestra colección de entrevistas a expertos en Tecnología Educativa. 